\title{
The Environmental Democracy under Political Siege in
}

\section{Turkey}

\author{
Hayrettin Kilic \\ The Green Think Tank of Turunch Foundation, Hoboken, New Jersey 07030, USA
}

\begin{abstract}
On June 24th, 2018, President Tayyip Erdogan, along with his pro-Islamic party, the Justice and Development Party, AKP, won the general election in Turkey, which will enable Mr. Erdogan to be a one-man ruler of the Republic of Turkey in the foreseeable future. Now, invested with infinite executive-presidential power, coupled with having complete control of the military, cabinet, judiciary and legislative branches, enables Mr. Erdogan to pursue his ambition to be a "nuclear power leader" in the Sunni Islamic world. The scientific denialism in general and environmental science, in particular, will reach a whole new level of insanity in Turkey where any conceivable environmental democracy will be abolished. The new government will further change the education establishment in every level and implement its anti-science political doctrines in which logic is an enemy and scientific truth is a menace. The last fifteen years of experience show that the AKP's politicians have become anti-science zealots who preach a dangerously new political cultism that is devoid of actual facts, if it does not fit their religious aberration narrative. Thus, virtually every aspect of the nuclear power program in Turkey will be a state secret under the control of one religiously motivated and driven ruler and this, should certainly sound alarm bells across the globe.
\end{abstract}

Key words: Environmental democracy, Turkish Nuclear Energy Project.

\section{Introduction}

On June 24th, 2018, President Tayyip Erdogan, along with his pro-Islamic party, the Justice and Development Party, AKP, won the general election in Turkey, opening a new chapter in the Turkish civilian and military nuclear saga which has been declining for the last 40 years. In July 2010, Mr. Erdogan, who was then the Prime Minister, concluded an intergovernmental agreement with Russia involving the transfer of nuclear energy technology to Turkey. A 20-billion-dollar contract was signed with the Russian company: Rosatom, to build a nuclear power plant and a nuclear fuel fabrication complex at the Akkuyu-Mersin site located on Turkey's eastern Mediterranean coastline. Under this agreement, the Russian company would develop a 4,800 MW nuclear power plant, consisting of four VVER-1200 reactors, on a BOO (Build-Own-Operate) basis. The Akkuyu

Corresponding author: Hayrettin Kilic, Ph.D., research fields: nuclear energy and environment. power plant site is near the Goksu delta which has the status of a nature reserve and is protected by Ramsar Convention.

Two years later, on May 3rd, 2013, a similar intergovernmental agreement, was finalized with the Japanese Government to establish another 4,800 MW nuclear power plant, consisting of four ATMEA1 reactors and a nuclear fuel reprocessing facility, in Sinop providence located on the southern shore of the Black Sea. A consortium comprising Mitsubishi Heavy Industry Ltd and Itochu of Japan, Areva and GDF Suez of France, would build a nuclear complex, based on BOO also, with an initial estimate of $\$ 22$ billion (US). The power plant site is within the Sarikum Lagoon and protected by the Ramsar Convention, as well as by the 1994 Black Sea Convention (Bucharest Convention).

However, in April of 2018, the Japanese trading house Itochu, which is major global financer of the nuclear weapon industry, was a contributor of $30 \%$ of this project's overall cost, withdrew from the joint 
Turkish Japanese nuclear power project, claiming that their decision was based on unforeseen cost overruns and stricter safety regulations. It is said that the Japan Bank of International Cooperation may cancel its 70\% present contribution at any time, which will in turn create a temporary halt in the Sinop project until China or South Korea makes a deal with Mr. Erdogan who can overrule any existing environmental restrictions.

A third nuclear power plant, again by the Black Sea, is now being planned in Inceburun-Igneada, approximately $150 \mathrm{~km}$ west of Istanbul and only 10 $\mathrm{km}$ from the Bulgarian border. This power plant will be built in one of the protected territories under the Ramsar Convention and Bucharest Convention, namely, the Igneada Sakha Longozu. It includes several small lakes, a river delta and undisturbed sand dunes with their characteristic unique xerophytic vegetation. There are questions as to whether China or South Korea will be the winning bidder to construct and operate this facility.

When complete, the Akkuyu and Sinop nuclear site will be the first and only nuclear power complex in the world under the control of an operator that is a subsidiary of a foreign, rather than sovereign, State, from construction through to the end of an undetermined decommissioning process. Furthermore, both cooperation agreements also include the promising establishment of foreign owned and operated nuclear fuel cycle programs, more specifically nuclear fuel reprocessing and fuel fabrication facilities in Turkey. According to article 2 of the Turkish Japanese agreement: "Technology and equipment for Uranium enrichment, spent nuclear fuel reprocessing, conversion of Plutonium and production of material including those items listed in part $\mathrm{C}$ of Annex A, as well as Plutonium may be transferred under this agreement only when this agreement is amended for that purpose in accordance with pyrograph 1 of Article 14" [1]. And so, the very real possibility arises of weapon grade nuclear material being manufactured by Russia or Japan within the borders of a member of the NATO alliance.

A sobering fact is that there is no technical demarcation between a military and civilian reactor nuclear program. "Commercial nuclear power is the foundation for nuclear weapons. If we had any chance to slow the spread of nuclear weapons, we needed to establish a control regime concerning the spread of commercial nuclear technology", said John J. Hamre, US Deputy Secretary of Defense 1997-1999, and US Undersecretary of Defense 1993-1997, President and Chief Executive Officer Center for Strategic and International Studies Washington, D.C..

Both, Turkish-Russian and Turkish-Japanese agreements include several clauses that permit the Turkish government to extract plutonium from spent fuel and to enrich Uranium. Simply, Turkey is embarking upon "weapon sensitive" technology. Therefore, there can be no clearer indication that these intergovernmental projects are geopolitically motivated and will provide a new breeding ground for nuclear weapon programs thinly disguised as "Nuclear Technology Transfer Agreements". The latest attempts by Turkey, the Arab Emirates and Jordan to embark on vigorous nuclear programs collectively show that the proliferation of nuclear power in the Middle East is now the greatest challenge [2].

\section{Rights of Access to Information, Public Participation in Decision-Making and Access to Justice for Akkuyu and Sinop Nuclear Power Project}

On December 11, 2013, the Turkish Ministry of Environment and Urban Planning issued a three thousand page, literally a cut and paste, EIA (Environmental Impact Assessment) report for the Akkuyu nuclear power plant project, and at this time, a similar EIA being prepared for the Sinop project. The EIA is supposedly subject to independent public hearings and approval of regional residence before it will be finalized. The AKP government brought 
members of their party from nearby cities by bus to be present in several public meetings in Mersin and Sinop Province. They provided accommodation and free lunches to the party members who attended. But local NGOs (Non-Governmental Organizations) and hundreds of people living in the in Mersin and Sinop who are opposed to the nuclear power plant projects were prevented by police from participating in the public hearings. After 30 days of a largely superficial review process, Mr. Erdogan sent a letter to every governmental institution involved in producing EIA report asking them to expedite their final approval of the EIA. A revised version of the EIA was approved by the AK government in December 2014.

Since then, for the Akkuyu project, 13 different complaints have already been filed against the Ministry of Environment and Urban Planning in the Mersin High Court. Numerous NGOs along with the UCTEA (Union of Chambers of Turkish Engineers and Architects), the Turkish Bar Association, Turkish Medical Association played a vital role in preparing technical and judicial arguments of the complaints. These complaints seek to challenge the scientific integrity of the EIA report and invalidate it on the following grounds; misrepresentation of or failure to itemize the radioactive inventory and projected releases into the environment; incomplete information about the toxic chemicals which will be injected into the cooling system throughout the nuclear complex; misleading information about the cooling water's temporal and chemical effects on marine life; lack of details on an emergency evacuation plan in case of a sewer accident; lack of a comprehensive waste management plan; unspecified insurance coverage for the nuclear complex as well as noncompliance with third party liability requirements. Coupled with these complaints are allegations that signatures on some sensitive reports contained or referred to in the EIA have been falsified.

After two years of appealing producers, the case reached to the Republic of Turkey Presidency of the
Council of State, DANISTAY, a Superme Consultative and Appelative Court, accept to review this case. Before rendering their final oponion for this case, the court had to rewiew the final certification of EIA which was produced by 15 lower court assigned experts to evaluate arguments that were filed against the approved EIA. According to rules and regulations these experts must be independent-impartial indivuals, however, they happened to be working in goverment universities. In spite of clear scientific evidence presented in the complaints, unfortniuatly, these academicians have relactend endorsed-certified the incomplete and ill-advised IEA.

The first and the last instance court of the Turkey, in March 2017, the Councel of State rendered its final descsion in which they admitted that, "After reviewing the arguments of complaints against to EIA which is endorsed by goverment assigned expert findings, the court recignizes that the EIA report before the court is inded incomplete imperfect and inadequate. However, in the court oponion, the deficiencies that are argued by plantaif did not arise to the level of in invalidating or cancelling the EIA for the Akkuyu Nuclear power Plant, and further, the court accepts the goverment assertion that all possible defisits that will be determined and fixed during the implimantation of the project in the future", which marks the beging of the end of existing envorimental laws and regulations in Turkey.

\section{Japan and France-Global Financial Involvement in Nuclear Weapons Program}

From the onset of the Cold War, the financial institutions that are directly or indirectly sponsored by governments have provided various types of financial services to nuclear-energy-weapon companies including loans, investment banking and asset management. Since January 2014, seven financial institutions in Japan made an estimated USD $\$ 18,555$ million available to 20 nuclear weapon producing companies in the USA and Europe. In France, 14 
financial institutions made an estimated USD $\$ 29.8$ billion available to nuclear weapon producing companies since January, 2014. The following Japanese banks, which are involved in the Sinop Project, are known to have significant involvement in providing loans, investment banking or holdings shares.

The Chiba Bank: US\$20 million; Mitsubishi UFJ Financial: US\$8.470 million; Mizuho Financial: US\$5.172 million; Nomura: US\$3 million; Orix Corporation: US\$610 million; Sumitomo Mitsui Financial US\$4.246 million; Sumitomo Mitsui Trust: US\$35 million [3]. The Japanese financial institution which is most significantly involved in the financing of one or more nuclear weapon companies in France is: The Ariane Group, which includes the Safran and Airbus of France.

\section{Inexorable Nuclear Power Program of Turkey}

If this proliferation of nuclear development was not sufficient cause for concern on its own, right after the presidential elections in June 2018, a new NRC (Nuclear Regulatory Commission) of Turkey, by a Presidential Degree, directly controlled and staffed by the president Erdogan, was established in July 2018 to oversee all future nuclear activities in Turkey. Worryingly, the budget, plans and programs of the NRC cannot be questioned or challenged, without the consent of the president Erdogan.

The new NRC is also charged to govern the TAEK (Turkish Atomic Authority) programs, which in turn are both the promoter and safety regulator of the nuclear energy industry in Turkey. In fact, both organizations are politically subordinate to the president's office and have no effective organizational power, scientific expertise or capacity to make independent rules, enforce compliance or impose international safety measures during both the construction and operational phases of the nuclear complex in Akkuyu and Sinop.

\section{Is Turkey Ready for a Nuclear Energy Program?}

Within the frame work of the IAEA (International Atomic Energy Agency), there is a committee known as the INIR (Integrated Nuclear Infrastructure Review) formed in 2009. It consists of IAEA staff and international experts that provide a comprehensive assessment of all facets of a nuclear power program upon the request of a member country.

The INIR mission is to guide the member country on everything from the creation of regulations to the necessary infrastructure, materials and technical expertise required for building a nuclear power program. At the reluctant request of the Turkish government, the INIR prepared a report concerning the Akkuyu project in general and the integrity of the EIA report in particular. The INIR report was delivered to the Turkish TAEK on February 20th, 2014.

The INIR report includes 24 major recommendations and 15 suggestions to assist the Turkish authorities and institutions to prepare the necessary infrastructure for the Akkuyu and Sinop projects. The main recommendations of the INIR report are that Turkey enacts a compressive law on nuclear energy; establishes an independent regulatory body; firmly adheres to international conventions and treaties relating to nuclear power in any shape or form, and, conducts an impartial EIA report free from political influence or pressure.

Without sayings as much, the report's findings were clear that the Turkish Government, with its existing inadequate legal and technological infrastructure, is far from capable or prepared to implement a safe and properly managed nuclear power program. Perhaps unsurprisingly, the report was kept secret by the Turkish government and was not revealed to the public until it was leaked to the media in June, 2015.

This structure of control and regulation of the nuclear energy, along with the passing of strict secrecy laws, similar to the 2015 Japanese Secrecy 
Laws, is an almost carbon copy of the Russian Nuclear Regulatory System and completely different from the accepted "norms" in the western part of the world. The Sinop Nuclear Complex will be a new extension of these obscured organizations under the personal protection of Mr. Erdogan.

\section{The Russian, Japanese and Turkish Nuclear Energy Authorities; No Safety Culture and Corruption Remain Endemic}

Turkey, Japan and Russia did not sign the convention on "Access to Information, Public Participation in Decision-Making and Access to Justice in Environmental Matters" known as AARHUS Convention. Russia is a developed state with the world's most inefficient economy, and the Russian nuclear industry and regulatory authority lacks transparency. They have neither the capacity nor the willingness to enforce the rules and regulations set out in their own nuclear safety codes.

The report of the Eco Defense and Transparency International Russia organization published in November 2010, showed that the corruption has "deeply imbedded" into almost every branch of Rosatom. Rosatom is, in essence, a "state within a state" operating under no one's control but its own. The Russian nuclear industry remains under almost no external control. The lack of transparency, widespread corruption, failure to demonstrate high levels of safety, and, the unresolved waste and decommissioning issues must be of high concern to any potential customer of Rosatom's on the international market. According to governmental sources, about 500 million tons of radioactive waste has accumulated at various facilities across Russia.

Corruption in Japan is arguably worse, a fact that Chiari Naito, the former vice president of Kansai Electric Power Co. (KEPCO-Japan), admitted when he disclosed secretly paying seven of Japan's prime ministers approximately $\$ 200,000$ per year, for 18 years (Mashable UK, July 28th, 2014). From the beginning of the peaceful use of nuclear energy, hundreds of nuclear industry executives and regulators in Japan and Russia have been arrested on the grounds of corruption. According to the US National Academy of Science report, titled Committee on Lessons Learned the Fukushima Nuclear Accident for Improving Safety and Security of U.S. Nuclear Plants. National Academy of Sciences [4] "Japan's safety rulemaking is deeply flawed. Because NISA lacks full-time technical experts to draw up comprehensive regulations, it depended largely on retired or active engineers from nuclear-industry-related companies to set rulemaking. While the Government of Japan acknowledged the need for a strong nuclear safety culture prior to the Fukushima Daiichi accident, TEPCO and its nuclear regulators were deficient in establishing, implementing, and maintaining such a culture. Examinations of the Japanese nuclear regulatory system following the Fukushima Daiichi accident concluded that regulatory agencies were not independent and were subject to regulatory capture."

\section{Environmental Concerns}

Ecological effects of a nuclear power plant on local marine life as well as the long-term geopolitical consequences have been generally overlooked and the Turkish EIA is no exception to this. Every use of the sea and its coastal areas has the potential to affect the well-being of neighboring countries. Even point-source pollution restricted to the vicinity of a nuclear power plant, may affect the economic development of another country by killing juvenile fish which would have otherwise migrated to its coasts. The Turkish commercial fishing industry, annually catches around 300,000 tons of anchovies alone - this will be the first "victim". Within 10 years, the Sinop and Igneada nuclear power plant's cooling system will severely deplete most of the marine life around the Black Sea Basin.

For thousands of years, the Mediterranean and Black Sea Basin inhabited by unique form of flora and 
fauna. Both Seas connect three continents, 27 nations, and, more than 700 million people. And both basins have been the cradle of most of the civilizations in our planet; the human population of the coastal countries heavily dependent of their needs for food, transport and recreation uses this marine ecosystem.

The Akkuyu and Sinop nuclear complex, from the onset of the construction, during the operations and possible unforeseen accidents, will have adverse impact on ecology, biogeography, economy and livelihood of people who thrive on the marine-ecosystem and tourism industry around the Mediterranean and Black Sea. These ill-conceived agreements also ignore vigorous adherence to the Barcelona and Basel Convention to protect the Mediterranean Basin, as well as the 1994 Black Sea Convention (Bucharest Convention).

In addition to chronic radioactive gas released every day, enormous quantities of water (10 billion litres per day) will be circulated throughout the Akkuyu and Sinop nuclear complex destroying billions of larva and other marine creatures, including planktonic organisms. Discharge water will also increase the temperature and change the chemical composition of the sea water.

The biological diversity and peculiarities of the Black Sea and Mediterranean Sea are well documented: "The Mediterranean Sea comprises less than $1 \%$ of the world's oceans, but it contains about $7 \%$ of all known marine species, including 357 species of reptiles, 115 amphibian species, 400 species of fresh water fish and 22,500 endemic vascular plants species". In the Black Sea, a total of 3,774 species have been identified, including: 1,619 fungi, algae and higher plants; 1,983 species of invertebrates; 168 species of fishes, and 4 species of mammals.

According to a detail United Nations report in Ref. [5], "The biologically rich regions are only limited to only oxygen rich shelf zones, with depths of up to $50-100 \mathrm{~m}$ in the southern coast line, and in the northern Black Sea shallow-water areas with depths of up to 5-10 meters. This water body, bordering the hydrogen sulphide zone, is approximately 200-300 meters wide and averages 5-50-metres-deep, in which high concentrations of fish eggs and larvae strive, and circulate counter clock wise along $4,340 \mathrm{~km}$ coastline of the Black Sea".

The high and low tides are practically non-existent in the Black Sea, which is why there are no typical estuaries-inlets-sounds in the Turkish coastline. Therefore, oxygen rich coastal water will be used as cooling water for both Sinop and Igneada nuclear power complexes. As a result, if the water-balance-boundary between lifeless Hydrogen Sulphide and biologically creative/productive regions of the Black Sea is disturbed and mixed that will be the beginning of the end of marine life in the Black Sea.

\section{Conclusion}

The founder of the Justice and Development Party, president Erdogan, is ambitious to create Turkey as a nuclear power leader in the Sunni Islamic world which is happening at any cost and, with little care for the environmental consequences. This should be a matter of global concern. Their willingness to adopt the lowest Russian-Japanese nuclear technology rather than the highest western standards of nuclear technology and regulations, the least rather than the most transparent of environmental impact procedures and the riskiest rather than the safest partners is contrary to all conventions and the best interests of the Turkish people.

In addition to existing Turkish energy dependence on Russian oil and natural gas, which can be supplied from different sources, the electrical energy produced at the Akkuyu and Sinop nuclear power plant will be at the mercy of the Mitsubishi and Rosatom companies. It is not, however, too late to draw back from the abyss. Even if cancelling the agreement with Russia and Japan involves payment of significant compensation it would be money well spent for the 
wellbeing of the Turkish people and the rest of the world.

\section{Acknowledgment}

The author would like to thank Mrs Marry Jimenez for her valuable comments. The Green Think Tank of Turunch Foundation is a nonprofit (501)(c)3 foundation in the United States, and does not accept any donations.

\section{References}

[1] "Agreement between the Government of Japan and the Government of the Republic of Turkey for Co-operation in the Use of Nuclear Energy for Peaceful Purposes." https://www.mofa.go.jp/mofaj/files/000018111.pdf.

[2] Kilic, H. 2016. "The Environmental and Ethical Issues of Nuclear Power and Ionizing Radiation." Journal of Environmental Science and Engineering A 5: 580-98. doi:10.17265/2162-5298/2016.11.006.

http://www.davidpublisher.com/index.php/Home/Article/ index?id=29764.html.

[3] 2108. Don't Bank on the Bomb Report. www. DontBankOnTheBomb.com.

[4] Committee on Lessons Learned from the Fukushima Nuclear Accident for Improving Safety and Security of U.S. Nuclear Plants. National Academy of Sciences. http://nap.edu/18294.

[5] A Study of Change and Decline ISBN 92-1-126042-6 United Nations Publications Sales No. 95. III.B.6 Black Sea Environmental Series, Vol. 3 Global Environment. 